\title{
Assessing Cultural Awareness towards Heritage Sites among Local Communities for Sustainable Tourism Development "The case of Qaitbay Castle in Alexandria"
}

Noha Kamel

\begin{abstract}
Qaitbay Castle is one of the most important heritage sites in Alexandria which has recently witnessed many negative practices. Therefore, this study evaluates the level of cultural awareness of residents in Qaitbay Castle area. It also investigates their gains from tourism advantages, as well as their participation in heritage preservation which helps achieving sustainable tourism development. The study was conducted through two methods: (1) interviews with managers in some tourism and heritage official institutions regarding their efforts to raise cultural awareness among local community; (2) A questionnaire to collect data from a random sample of 570 residents in the area of Qaitbay Castle. Four hundreds and eighty one questionnaires were valid to be analyzed. The results revealed the weakness of residents' cultural awareness and the lack of integrated program between the official authorities to enhance cultural awareness. Finally, some suggestions for enhancing community's awareness were proposed for managers and policy makers.
\end{abstract}

\section{Keywords:}

Cultural Awareness, Heritage Sites, Heritage Preservation, Sustainable Tourism Development, Local Community, Qaitbay Castle.

\section{Introduction}

Recently, several publications have been published confirming the importance of heritage preservation. Most of these publications, especially in Egypt, dealt with the significance of cultural heritage conservation both tangible and intangible. ${ }^{1}$ In addition, some researchers focused on the problems and challenges that face the cultural heritage in Egypt. ${ }^{2}$ Other researchers discussed the importance of engaging community whether in heritage conservation or in sustainable tourism development ${ }^{3}$. Few studies examined community's awareness and attitudes towards cultural heritage. ${ }^{4}$ Subsequently, there are still limited studies, especially in Alexandria, examining the importance of residents' cultural awareness and participation in heritage preservation for achieving sustainable tourism in heritage sites.

Therefore, the recent study aims at (1) assessing the level of residents' cultural awareness towards Qaitbay Castle as a significant heritage site in Alexandria; (2) investigating their gains from tourism advantages;(3) discovering whether they participated in heritage preservation in their region or not;(4) highlighting the role played by official authorities regarding cultural awareness in local communities; and finally (5) emphasizing the importance of cultural awareness and local participation in heritage preservation for achieving sustainable tourism development. The study is divided into two sections. Firstly, the literature review

\footnotetext{
${ }^{1}$ Estav Setyagung et al., "Preserving Cultural Heritage: The Harmony between Art Idealism, Commercialization, and Triple-Helix Collaboration." American Journal of Tourism Management 2, no.1 (2013): 22-28; Gunlu Ebru, Ptrnar Ige, Kamil Yagci, "Preserving Cultural Heritage and Possible Impacts on Regional Development: Case of İzmir,” International Journal of Emerging and Transition Economies 2, no.2 (2009): 213-229.

${ }^{2}$ Heba Abdelnaby., "Problems and Challenges of Cultural Heritage in Alexandria, Egypt," International Journal of Culture and History 3 , no. 3 (September 2017): 174-178; EHK Yung and Chan EHW, "Problem issues of public participation in built-heritage conservation: two controversial cases in Hong Kong," Habitat international 35, no. 3 (2011): 457-466.

${ }^{3}$ P. Dyer et al., "Structural Modeling of Resident Perceptions of Tourism and Associated Development on the Sunshine Coast, Australia." Tourism Management 28, no. 2 (2007): 409- 422; K.L. Andereck and G.P Nyaupane “Exploring the Nature of Tourism and Quality of Life Perceptions among Residents," Journal of Travel Research 50, no.3 (2011):248-260.

${ }^{4}$ Nyaupane Gyan and Dalle Timothy, "Heritage Awareness and Appreciation among Community Residents: Perspectives from Arizona, USA," International Journal of Heritage Studies 16, no. 3 (2010): 225-239; Amanda Cecil et al., "Exploring Resident Awareness of Cultural Tourism and Its Impact on Quality of Life." European Journal of Tourism Research 1, no. 1 (2008):39- 46.
} 
outlines the main points of the research. The second section is dedicated to the field study including: research methodology followed by results and discussion. Finally, the study presents some recommendations that may contribute towards creating cultural awareness among the Alexandrian community.

\section{Literature Review}

\subsection{Cultural Awareness for Heritage Sites Preservation}

Cultural awareness is a critical issue for achieving heritage conservation. ${ }^{5}$ It is about understanding the meaning of culture and heritage in the country. It helps locals to become familiar with their own and others' cultural heritage. ${ }^{6}$ People can't recognize other cultures while they don't have enough knowledge about their own heritage and civilization and behave positively towards it. Improving locals' knowledge regarding the cultural heritage is required to promote their sustainable behavior at heritage sites. ${ }^{7}$ So, heritage preservation needs commitment and support from local community. ${ }^{8}$

H1. Residents' behavior towards heritage site is affected by their cultural knowledge.

Despite the significance of the cultural heritage for tourism destination and the existence of wide diversity of heritage sites in Alexandria, they are still witnessing many threats and problems due to the lack of community's cultural awareness, such as danger of commercialization, loss of authenticity and damage. ${ }^{9}$ Managing heritage and tourism in Egypt is running by four main official institutions; Ministry of Tourism, Tourism Promotion Authority, Tourism Development Authority and Ministry of Antiquities. These authorities are supposed to be responsible for raising cultural awareness in local communities to promote tourism and preserve cultural heritage. Nevertheless, there is no collaborative work or joint plan between these bodies directed through organized methodology to raise locals' awareness regarding the significance of heritage sites. Miserably, each authority works separately. Also, some of them believe that enhancing cultural awareness is not considered a part of their work. In addition, despite the existence of some NGOs and initiatives that interested in culture and heritage; such as Save Alex, AlexMed and My society, they couldn't raise cultural awareness among the local community. For example, AlexMed pays more attention to research in heritage, rather than spreading cultural awareness. Others launch awareness campaigns after a heritage site or historical building that faces real danger, rather than acting before the damage happens, such as SaveAlex. ${ }^{10}$ Achieving that requires a planned comprehensive program defining the role of each authority and different techniques tailored to fit various groups in the local community.

Initially, policy makers and key actors have to be considered in the awareness programs through various methods, such as roundtable discussions, press conferences and meetings with experts in tourism and archeology, to discuss policies and procedures that ensure the protection of heritage sites. ${ }^{11}$ Secondly; the relevant authorities should educate students in both governmental and private schools about the cultural heritage and its importance. Curriculum must be designed to include subjects related to heritage and tourism, such as tourism awareness, cultural heritage and heritage protection; besides the traditional topics which are already being taught in schools. According to Asta, teaching heritage and tourism can be done through formal education curricula or via informal methods, such as Gamified Learning, which is described in several recent literatures as a modern effective tool to increase student motivation and interaction ${ }^{12}$. It is based on the use of game design elements and game mechanics in non-game contexts. ${ }^{13}$ Likewise, schools can organize an open day for cultural heritage every semester as a new method for raising students' awareness and making exhibit of heritage that contains products and crafts

\footnotetext{
${ }^{5}$ Fadzlin Bakri et al., "Public Perception on the Cultural Significance of Heritage Buildings in Kuala Lumpur." Journal of Social and Behavioral Sciences 202 (2015): 294-302

${ }^{6}$ Idilfitri Sabrina et al.," Public Perception of the Cultural Perspective towards Sustainable Development." Social and Behavioral Sciences 168 (2015):191203.

${ }^{7}$ Piera Buonincontri, Alessandra Marasco and Haywantee Ramkissoon, "Visitors' Experience, Place Attachment and Sustainable Behavior at Cultural Heritage Sites: A Conceptual Framework,” Journal of Sustainability 9, no.7 (2017): 1-19.

${ }^{8}$ Andereck and Nyaupane, «Exploring,» 248-260; Nyaupane and Timothy, «Heritage,» 225-239.

${ }^{9}$ Peter Gould and Paul Burtenshaw," Heritage Sites: Economic Incentives, impacts, and Commercialization,” In: Encyclopedia of Global Archaeology, edited by Claire Smith (Springer, London, UK, ) 3326-3331

${ }^{10}$ Abdelnaby,»Problems," 177.

${ }^{11}$ Piera et al., «Visitor $>\mathrm{S}, » 1-19$.

${ }^{12}$ Adukaite Asta, Lorenzo Cantoni and Izak Zyl, "The role of digital technology in tourism education: a case study of South African secondary schools," Journal of Hospitality, Leisure, Sport and Tourism Education 19 (2016): 54-65.

${ }^{13}$ Josebasaenz et al, "Gamifying Learning Experiences: Practical Implications and Outcomes," Computers and Education 63 (April 2013$)$ : 380.
} 
manufactured by local craftsmen; as well as inducing students to participate in the preparation of this day. ${ }^{14}$ Thirdly, training courses should be provided to college students in universities, especially Tourism and Hotels Faculties and Institutions to participate with relevant bodies as better educators in awareness campaigns that will take place in schools. ${ }^{15}$ Furthermore, the study of Nyaupane and Timothy emphasized on the importance of spreading awareness among parents and teachers via awareness-raising meetings and sensitization dialogue workshops to facilitate discussions about the history of heritage sites. ${ }^{16}$ Finally, there are other different methods to build better awareness among local community in general, such as walked tours, sound and light shows; as well as heritage festivals which reflect the local rituals, customs and traditions of the local area, along with disseminating an effective messages via media channels about the importance of heritage conservation for the tourism industry. ${ }^{17}$

\subsection{Residents Participation in Heritage Preservation}

Residents' participation in heritage protection has recently become a major concern in the tourism industry. It helps achieving sustainable tourism development in heritage sites. ${ }^{18}$ Cultural awareness is one of the main factors influencing residents' successful involvement in heritage conservation process. It drives them to take responsibility for their nation's heritage. Residents were not able to participate in preserving heritage sites -where they live- as long as they don't appreciate the historical value of these sites. The efforts made by official bodies and key actors to develop and preserve heritage sites, even if they are based on a topdown planning approach, will be futile with the absence of the community's cultural awareness and participation. ${ }^{19}$

H2. Local residents' participation in heritage site preservation is affected by their level of cultural awareness.

On the other hand, residents in the host communities must recognize that tourism activity in heritage sites not only benefits cultural tourists who are interested in gaining knowledge about different cultures, but also provides positive economic, environmental and social impacts to them. ${ }^{20}$ They have to realize that preserving heritage attractions contributes in achieving a better quality of life for them. When local residents feel benefited from the tourism activity in their area, their support and participation in heritage preservation and tourism development will increase. ${ }^{21}$ As said by Munhurrun and Naidoo, for the success of residents' participation in heritage site preservation, it is important to examine their attitudes and perceptions towards tourism benefits. Thus, the community oriented approach should be adopted to achieve community's involvement in the process of heritage conservation. ${ }^{22}$

\section{H3. Local residents' participation in heritage site preservation is affected by their gains from tourism advantages.}

Therefore, preserving cultural resources has become a major challenge in the world, especially in developing countries. Residents' participation is often used as a strategic approach for heritage preservation and sustainable local development. But, it is rarely applied in developing countries because of two main reasons; lack of suitable scientific planning for utilizing heritage regions in terms of sustainability and community participation, ${ }^{23}$ and limited awareness of residents, especially in popular areas, such as Qaitbay area towards heritage and tourism. ${ }^{24}$ According to Mamhoori, heritage preservation initiatives will be effective

\footnotetext{
14 Tarek Ahmed, “Assessment of Students” Awareness of the National Heritage, Case study: The Preparatory Year Students at the University of Hail, Saudi Arabia," Cogent Social Sciences 3, no.1 (2017): 1-26.

${ }^{15}$ SavitaSrivastava, "A Study of Awareness of Cultural Heritage among the Teachers at University Level," Universal Journal of Educational Research 3 (2015) $336-344$.

${ }^{16}$ Nyaupane and Timothy, «Heritage Awareness,»225-239.

${ }^{17}$ Yi-Ping Wang, “A Study on Kinmen Resident's Perception of Tourism Development and Culture Heritage Impact," Eurasia Journal of Mathematics, Science \& Technology Education 12, no.12 (2016): 2909-2920.

${ }^{18}$ Dallen Timothy and Boyd Stephen, Heritage Tourism (Harlow: Prentice Hall, 2003).

${ }^{19}$ Idilfitri et al., "Public," 191-203.

${ }^{20}$ Mbaiwa, J.E, "The socio-economic and environmental impacts of tourism development on the Okavango Delta, North-Western Botswana," Journal of Arid Environments 54 (2003): 447-467.

${ }^{21}$ Dyer et al., "Structural,"248-260; ChrisChoi and SirakayaErcan, "Measuring Residents' Attitude toward Sustainable Tourism: Development of Sustainable Tourism Attitude Scale.” Journal of Travel Research 43 (2005): 380-394; B.C. Kaae, “Tourism, Recreation and Sustainability,” In: The perceptions of tourists and residents of sustainable tourism principles and environmental initiatives, edited by McCool, S.F. and Moisey, R.N (Wallingford, 2000) 289-314.

${ }^{22}$ RamseookMunhurrun and Perunjodi Naidoo, "Residents' Attitudes toward Perceived Tourism Benefits," International Journal of Management and Marketing Research 4, no.3 (2011): 45-56.

${ }^{23}$ Ch'aska Huayhuaca et al., "Resident Perceptions of Sustainable Tourism Development: Frankenwald Nature Park," International Journal of Tourism Policy 3, no. 2 (July, 2010): 126.

${ }^{24}$ Ahmed, "Assessment,"1-26.
} 
if it depends on both understanding and participation of the local community. ${ }^{25}$ Parallel to providing appropriate cultural awareness programs for residents, they should get benefited from the tourism activity in the heritage site in terms of achieving a better quality of life for them at all levels. ${ }^{26}$ Local residents need to be connected to the heritage site in a way that motivates them to protect and maintain the site. This typically leads to achieving sustainable tourism development in heritage sites. Cultural awareness and local participation are two main pillars of sustainability. So, raising cultural awareness and achieving active involvement of residents in heritage preservation will lead the region towards sustainable tourism development, achieving its three dimensions: Socio-Cultural; through increasing residents' belonging to the region, respecting cultural heritage and fostering relations between locals and tourists, Economical; by opening fields of work for residents, providing small projects of handicrafts and local products, improving the standard of living and increasing income, and Environmental; through preserving cultural assets, reducing negative practices in heritage areas, promoting sustainable behaviors and depending on eco-friendly localproducts. ${ }^{27}$

\subsection{Qaitbay Castle}

Qaitbay Castle is one of the most important defensive fortresses on the Mediterranean Sea Coast. It was built in the year 884 Hijri by the Sultan Al Ashraf Qaitbay Mamlouke in the place of the famous ancient Alexandria lighthouse on the eastern point of Pharos Island. Thus, it has an important location on the entrance to Alexandria's eastern harbor. Qaitbay Castle was known as one of the most important Islamic monuments in Alexandria. ${ }^{28}$ Also, it is considered a tourist attraction for many visitors and tourists along the year both international and domestic. ${ }^{29}$ Despite that, Qaitbay Castle has recently witnessed many negative practices by residents and managers which aren't appropriate to its great historical value. It has been turned into a wedding hall that attracts families and night buses to this site for tourism promotion, which resulted in a great controversy between archaeologists and tourism experts ${ }^{30}$. Therefore, the current study was conducted on the region of Qaitbay Castle as a significant heritage site in Alexandria, to assess the level of residents' awareness in the context of heritage and tourism.

\section{Methodology}

The study relies on a descriptive analytical methodology in order to explain related issues of the phenomenon under study. The study targeted the residents in the region of Qaitbay Castle and the managers in some tourism and heritage official institutions who work in heritage conservation. The study was conducted in November 2017 till the end of February 2018.

\subsection{Sample and Data Collection Instruments}

In order to achieve the objectives of the study, a descriptive research was adopted using a quantitative approach to collect and analyze data on the phenomenon and drawing conclusions about the research problem, focusing on Qaitbay Castle as a case study. Saunders et al. noted that the case study approach is appropriate for both descriptive and investigative researches. So, a single case has been chosen and conducted in the current study to provide a deep view about the phenomenon. ${ }^{31}$

The study was conducted through two methods of data collection. Firstly; semi structured interviews were conducted with (11) managers in some official institutions that are supposed to be responsible for raising cultural awareness in local communities, such as: Ministry of Antiquities (The Management of Cultural Development and Archaeological Awareness, The Area of Alexandria, which belongs to the Ministry of Antiquities), Ministry of Tourism, Tourism Promotion Authority,

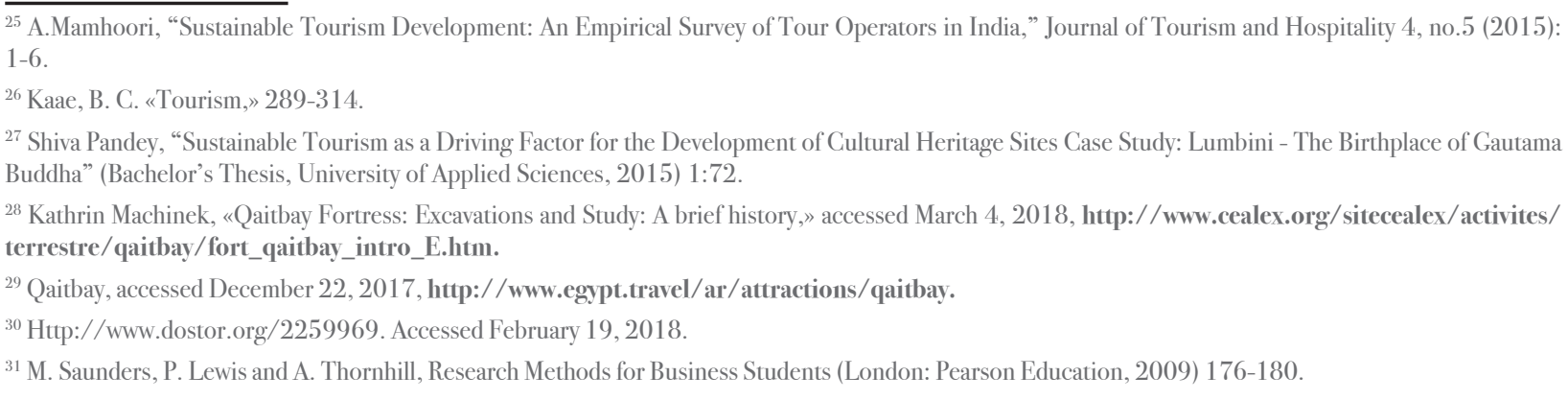


Museum of Antiquities in Alexandrina Bibliotheca*32 and the Faculty of tourism and hotels- Alexandria University. The study has chosen personal interviews as it allows an in-depth understanding of the phenomena, observation of the behavior; as well as the flexibility to ask more questions. During November 2017; managers in the selected institutions were firstly contacted by phone to explain the idea of the study and were nicely asked to participate in the research by setting appointment to get the required data. Later, interviews were conducted with 3 of the selected institutions. Each interview took time between 45 minutes and 1 hour. Others answered the questions via phone calls upon their request.

Five main questions were used to guide the in-depth interviews aiming to collect information and capturing a clear picture regarding the role played by the selected authorities to enhance community's awareness. The interview questions were formulated according to Monotoya's approach concerning constructing interview questions. ${ }^{33}$ These questions are: Q1. What are the recent awareness campaigns that were done concerning Qaitbay Castle? Q2. Do the governmental authorities implement an integrated plan for enhancing locals' awareness? Q3. What are the key obstacles that hinder this implementation? And what are the factors that might facilitate it? Q4. What is your opinion regarding what happened recently in Qaitbay Castle by exploiting it as a wedding hall in order to promote tourism? Q5. What do you think about community participation in heritage preservation?

Secondly; a questionnaire was designed and conducted in the region of Qaitbay Castle in Alexandria. The questionnaire was used as one of the most important methods of statistical data collection. It was designed using a five-dimensional Likert scale from 1 to 5 (1 strongly disagree and 5 strongly agree). The study population includes all residents in Qaitbay Castle area to make the local community as close as possible. The current study depends on a random sample as one of the sampling methods to achieve the study goals. Five hundred and seventy $(570)$ questionnaires were distributed among the targeted sample including: general public, service providers, souvenirs sellers, local craftsmen, students and taxi drivers. The total number of collected questionnaires were (492) questionnaire. Four hundred and eighty one questionnaires of them were valid to be analyzed representing a response rate (84.4\%). The study relied on the Statistical Package for Social Sciences (SPSS) for all the analyses through the following statistical methods: Frequencies; Mean, Standard Deviation, Analyses of Variance and Regression analysis.

The questionnaire was divided into five sections: $(A)$ highlights residents' profile characteristics; $(B)$ evaluates their level of cultural awareness towards Qaitbay Castle through two dimensions of cultural awareness (knowledge and behavior); $(C)$ discovers their gains from tourism advantages. Section $(D)$ investigates to what extent they participate in taking responsibility for heritage protection. At the end, it was necessary to evaluate the current status of the educational role played by schools in the region of Qaitbay Castle in developing students' awareness. As said by Cooper and Shepherd, tourism education is one of the methods used to build cultural awareness. ${ }^{34} \mathrm{So}$, section $(E)$ examines this issue in preparatory and secondary governmental schools in Qaitbay area, targeting twelve- to eighteen years old students, whose number were 142 students.

All the constructs in the questionnaire were adopted from previous researches and modified according to the current study's objectives. Section $B$ was derived from Youssef et al.; Yamaguchi \& Takada and Kisusi ${ }^{35}$; Section $C$ from Munhurrun and Huayhuaca et al. ${ }^{36}$; Section $D$ from Rasoolimanesh \&Jaafar's research ${ }^{37}$; and Section $E$ from Ahmed's study. ${ }^{38}$ It is worth mentioning that most residents of Qaitbay Castle area couldn't read or understand English. So, the researcher translated the questionnaire into Arabic language to be easily understood by respondents in order to guarantee a high response rate. After translation, the questionnaire was reviewed by Arabic language professionals and was modified according to their observations before being distributed.

\footnotetext{
${ }^{*}{ }^{32}$ Museum of Antiquities in Alexandrina Bibliotheca has been chosen because it aims at promote cultural awareness among young people through a variety of educational activities and has many actions in this regard. (Antiquities Museum accessed December 10, 2017. http://Antiquities.Bibalex.Org/Home/ Index.Aspx? Lang=Ar)

${ }^{33}$ Castillo Montoya, "Preparing for Interview Research: The Interview Protocol Refinement Framework," The Qualitative Report 21 , no.5 (2016): 811-831.

${ }^{34}$ Chris Cooper and Rebecca Shepherd, "The Relationship between Tourism Education and the Tourism Industry: Implications for Tourism Education," Tourism Recreation Research 22, no.1 (1997): 34-47.

${ }^{35}$ Youssef et al., "University," 1-65; Kisusi, "Promoting," 1-142; Y.S. Poong, S. Yamaguchi and J. Takada, “ Impact of Learning Content on World Heritage Site Preservation Awareness In Town of Luang Prabang, Lao Pdr: Application of Protection Motivation Theory," Annals of the Photogrammetry, Remote Sensing and Spatial Information Sciences, Volume 2, no.5 (September 2015): 251-265.

${ }^{36}$ Munhurrun and Naidoo, “Residents,» 45-56; Huayhuaca et al., «Resident,» 125- 141.

${ }^{37}$ Mostafa Rasoolimanesh and Mastura Jaafar, "Community Participation toward Tourism Development and Conservation Program in Rural World Heritage Sites," In: Tourism - From Empirical Research towards Practical Application, edited by: Leszek Butowski, (IntechOpen, 2016$) 1: 14$.

${ }^{38}$ Ahmed, “Assessment,"1-26.
} 


\subsection{Questionnaire Validity Analysis}

Before verifying the objectives of the study and analyzing the questionnaire, reliability coefficient analysis by using Cronbach's Alpha was calculated in order to measure the internal consistency of the items measuring each section. Table 1showed that the computed indices of Cronbach's Alpha for the study variables had moderately high reliability coefficients, ranging between $(0.722-0.826)$, which exceeds 0.70 for each section. This means that the collected data are reliable according to Nunnally and Bernstein(1994). ${ }^{39}$

Table (1): Internal reliability “Cronbach’s Alpha” for questionnaire’s sections

\begin{tabular}{|l|l|l|l|l|}
\hline & CULT.A1 & GTA2 & LRP3 & SR4 \\
\hline Cronbach's Alpha & 0.803 & 0.722 & 0.781 & .826 \\
\hline No. of items & 12 & 6 & 4 & 4 \\
\hline No. of respondents & 481 & 481 & 481 & 142 \\
\hline $\begin{array}{l}\text { 1CULT.AW: Cultural Awareness } \\
\text { 2GTA: Gains from Tourism Advantages } \\
\text { 3LRP: Local Residents Participation } \\
\text { 4SR: Schools' Role in Raising Awareness }\end{array}$ \\
\hline
\end{tabular}

\section{Results and Discussion}

\subsection{Interviews results}

The results of the conducted interviews are demonstrated as follows:

Regarding question 1; interviewees explained that there were no cultural awareness campaigns targeting Qaitbay Castle area in particular. A low percentage of them (18.2\%) mentioned that the area of Qaitbay Castle was one of the field visits which was carried out by the Management of Cultural Development and Archaeological Awareness as a part of a comprehensive program to visit some heritage areas in Alexandria to raise local's awareness regarding heritage and its significance; as well as the acceptable behaviors inside heritage attractions. In addition, some of these authorities $(45.4 \%)$ carried out visits to some schools inside Alexandria, including schools in the region of Qaitbay. But, these visits are not performed continuously or according to a structured schedule.

Concerning question2; the results showed that, in general, there was no coordination between the official Parties in the field of heritage and tourism. About (72.7\%) of interviewees clarified that they carried out separate campaigns in this regard. This result is corresponding to AbdelNaby's research, in which she noted that each authority or institution in the field of heritage and tourism works independently in its own field not in cooperation with the other entities. Similar outcomes were also confirmed by interviewees. Managers in the Egyptian Ministry of Tourism and Tourism Promotion Authority said that most of their campaigns were limited only to the tourist side and had no cultural side. Most of their activities are generally aimed at developing rural areas, discovering modern trends in tourism market and investigating tourism markets profile. ${ }^{40}$ However, it is well-known that tourism and culture are two sides of one coin as noted by many authors. ${ }^{41}$ It was illustrated that the Management of cultural development in Alexandria is the most authority interested in cultural awareness programs.

Consequently, the cooperation between the surveyed bodies rarely takes place as revealed by the majority of interviewees and when it happens, it is done on a limited scale. For example, the collaboration which sometimes occurs between Tourism Promotion Authority, Ministry of Tourism and Management of Cultural Development is mostly limited to providing the latter with publications, photographs and printed materials during its awareness campaigns in some areas, including Qaitbay Castle, Roman Theater, Kum Elshokafa, Anfushi and Kom Alnadora. Moreover, (81.8\%) of interviewees clarified that there were no specific programs or campaigns aiming at minimizing citizens' negative behaviors in heritage sites. In this context, $(27.2 \%)$ of

\footnotetext{
${ }^{39}$ J.C. Nunnally and I.H. Bernstein, Psychometric Theory (New York: McGraw-Hill, 1994).

${ }^{40}$ Abdelnaby, «Problems,” 177.

${ }^{41}$ Mamhoori, "Sustainable,” 1-6; Choi and Sirakaya, «Measuring,» 380-394
} 
interviewees explained that the ministry of tourism has already conducted a competition in a scientific research about citizens' behaviors in cultural attractions towards tourists and heritage preservation. Indeed, many studies have been published in this regard and a set of recommendations were provided, but unfortunately, there is no actual implementation of these suggestions. Furthermore, the findings revealed the absence of the role played by Tourism and Hotels Faculties and institutions in enhancing cultural awareness in local communities; even though their field of work and study is related to a great extent to this subject. They are supposed to work in an interactive manner with the official parties.

As for question 3; generally all the interviewees agreed that they are facing some obstacles that hinder them to implement effective awareness campaigns or design an integrated plan between the relevant authorities. These obstacles are as follows correspondingly:

- The lack of sufficient budget; for example officials in the Management of Cultural Development emphasized that they depend totally on their own resources and volunteers.

- The difficulty of coordination with other external institutions; such as schools and universities; more than half of interviewees noted that schools often refuse welcoming such campaigns; they believe that this impedes the educational process.

- $\quad$ The limited cooperation among the concerned Parties.

- The lack of top management conviction of the importance of awareness campaigns; lately, despite developing three awareness campaigns which have been designed according to a detailed timetable in the Ministry of Tourism, none of these programs were carried out because the top management and decision makers are not convinced about these campaigns. These programs were as follows; "Tourism is the responsibility of the community"; "Spreading and deepening tourism awareness among the Egyptian people"; and the initiative of "The Ministry of Tourism's employees are in the service of the Egyptian street".

Hence, it can be said that the identification of these barriers is required to solve them. The high percentage of interviewees (90.9\%) suggested that awareness campaigns can be favorably applied when efforts made by the concerned authorities are being united. Furthermore, they should understand the importance of awareness campaigns to preserve heritage sites and show tourism activity in a proper manner. When it occurs, these parties will be keen to solve the previous problems and work toward the success of these campaigns. Other suggested factors were as follows respectively: supporting and activating awareness programs that had been actually planned; having good relationships with external institutions will help in applying effective awareness campaigns; allocating sufficient budget for awareness campaigns; as well as having a high-quality database about the neglected heritage sites in Alexandria and start with local people in those areas.

On the issue of question 4; more than half of interviewees (54.5\%) perceive that using Qaitbay Castle as a place to hold weddings is totally unacceptable. They added that Qaitbay Castle is a significant historical symbol that expresses Egypt and one of its outstanding monuments which is not appropriate for such events. Thus, the utilization of the Castle must be consistent with its value and away from any negative practices that may cause damage; especially with the negative behaviors of many people in the Egyptian society. The other percentage (45.5\%) agreed that there is no objection to exploit the Castle in this way similar to the advanced countries; in order to promote tourism, only if taking into account the value of the impact which may happen. They emphasized that this must take place under the supervision of the relevant authorities and according to a strict set of laws and procedures to ensure that no damage, loss or destruction will happen. But if there is a possibility of slight harm may happen then, this matter will be considered objectionable. Finally, regarding question 5; even though (81.8\%) of managers are convinced that community participation is essential and required for heritage preservation, they stated that this process is still at improper levels and needs much improvement, which is in line with the study of Rasoolimanesh and Jafaar, in which they asserted that local residents should be involved in conservation programmes to ensure sustainability in heritage site $^{42}$. Therefore, community members have to be considered when planning or developing heritage sites, as they are able to contribute effectively to preserve their own future. ${ }^{43}$

\footnotetext{
$\overline{42}$ Rasoolimanesh and Jaafar, "Community,"3-4.

${ }^{43}$ Idilfitri et al., "Public," 194-195.
} 


\subsection{Questionnaires Results}

\subsubsection{Sample profile characteristics}

The following table shows the distribution of the sample according to their demographic characteristics:

Table (2): Respondents’ Demographic Characteristics

\begin{tabular}{|c|c|c|c|c|c|c|c|c|c|c|c|c|}
\hline \multicolumn{4}{|c|}{ Gender } & \multicolumn{3}{|c|}{ Age } & \multicolumn{3}{|c|}{ Educational Level } & \multicolumn{3}{|c|}{ Level of Income } \\
\hline \multicolumn{2}{|c|}{ Male } & \multicolumn{2}{|c|}{ Female } & \multirow{2}{*}{$\begin{array}{c}\text { Category } \\
\text { Less than } 18\end{array}$} & \multirow{2}{*}{$\frac{\text { No }}{138}$} & \multirow{2}{*}{$\frac{\%}{28,7}$} & \multirow{2}{*}{$\frac{\text { Category }}{\text { Preparatory school }}$} & \multirow{2}{*}{$\frac{\text { No }}{65}$} & \multirow{2}{*}{$\frac{\%}{13.5}$} & \multirow{2}{*}{$\frac{\text { categoty }}{\text { None }}$} & \multirow{2}{*}{$\frac{\text { No }}{173}$} & \multirow{2}{*}{$\frac{\%}{35.9}$} \\
\hline No & $\%$ & No & $\%$ & & & & & & & & & \\
\hline 296 & 61.5 & 185 & 38.5 & From 18:30 & 95 & 19.8 & $\begin{array}{c}\text { Senior secondary } \\
\text { school }\end{array}$ & 77 & 16 & Less Than 1200 & 96 & 19.9 \\
\hline & & & & From 31:45 & 166 & 34.5 & $\begin{array}{c}\text { Institute/ Technical } \\
\text { graduate }\end{array}$ & 157 & 32.6 & From1200:1700 & 114 & 23.7 \\
\hline & & & & $\begin{array}{l}\text { More than } \\
\quad 45\end{array}$ & 82 & 17 & Undergraduate & 33 & 6.9 & From 1800:2400 & 57 & 12 \\
\hline & & & & & & & Bachelor degree & 149 & 31 & 2500 and more & 41 & 8.5 \\
\hline
\end{tabular}

Table 2 interpreted that over half of the respondents are males (n $\quad 296,61.5 \%)$ while females represented $(\mathrm{n} \quad 185,38.5 \%)$ of the sample. Regarding the age range of respondents, the majority of the sample are ranged between " 31 to 45 ” years old (n 166, 34.5\%) who had the highest percentage. Whilst, (n 138, 28.7\%) of the sample were in the age category" Less than 18 ", followed by the age range from " 18 to 30 " at a rate of (n $\quad 95,19.8 \%$ ). The least proportion reported (n $82,17 \%$ ) was for the age "More than 45". By studying the educational level, it was shown that (n 157, 32.6\%) of respondents are technical graduates, followed by those who held a bachelor degree at a rate of (n $149,31 \%$ ) of respondents. As for students from preparatory and secondary schools, they represented (n 142, 29.5\%) of the sample. Only (n 33, 6.9\%) of the sample were undergraduate. Finally, concerning the monthly income, firstly (n $173,35.9 \%$ ) of respondents didn't get income. This is attributable that $(29.5 \%)$ of the sample are students as mentioned previously, besides, $(6.4 \%)$ of respondents didn't work. As for the remaining percentage, it was shown that the highest percentage ( $\mathrm{n} \quad 114,23.7 \%$ ) went for those who received income ranged between 1200 and 1700 L.E per month, followed by (n 96, 19.9\%) who received monthly income less than 1200.This indicates that the monthly income of (43.6\%) of the surveyed sample does not exceed 1700 L.E per month. 


\subsubsection{Descriptive Analysis of Study Variables}

A descriptive analysis of study variables has been conducted and summarized in Table 3.All the statements in each section have been rearranged in an ascending order according to mean scores as shown below:

Table (3) Descriptive Analysis of Study Variables (M \& SD)

\begin{tabular}{|c|c|c|c|c|c|c|c|}
\hline & Statement & M & $\mathrm{SD}$ & & Statement & M & $\mathrm{SD}$ \\
\hline \multicolumn{8}{|c|}{ Level of Cultural Awareness (CULT.AW) } \\
\hline & & Overall S & re $(\mathrm{M}$ & $1350 \&$ SD & $0.4182)$ & & \\
\hline \multicolumn{2}{|r|}{ CULT.K (Knowledge) } & 2.14 & 0.516 & \multicolumn{2}{|r|}{ CULT.B (Behavior) } & 2.131 & 0.505 \\
\hline $\begin{array}{l}\text { CULT. } \\
\text { K1 }\end{array}$ & $\begin{array}{l}\text { Interested in gaining knowledge } \\
\text { about tourists experiences }\end{array}$ & 1.80 & .909 & CULT.B1 & $\begin{array}{l}\text { Have the ability to deal with } \\
\text { tourists from different cultures }\end{array}$ & 1.60 & 0.833 \\
\hline $\begin{array}{l}\text { CULT. } \\
\text { K2 }\end{array}$ & $\begin{array}{c}\text { Know that residents play an } \\
\text { important role in preserving } \\
\text { Qaitbay Castle }\end{array}$ & 1.85 & 1.134 & CULT.B2 & $\begin{array}{c}\text { Visited many historical places in } \\
\text { Alexandria }\end{array}$ & 1.73 & 0.916 \\
\hline $\begin{array}{l}\text { CULT. } \\
\text { K3 }\end{array}$ & $\begin{array}{c}\text { Know the historical features of } \\
\text { Qaitbay Castle. }\end{array}$ & 1.875 & 0.949 & CULT.B3 & $\begin{array}{l}\text { Follow the rules and instructions } \\
\text { inside the Castle }\end{array}$ & 1.91 & 0.988 \\
\hline $\begin{array}{l}\text { CULT. } \\
\text { K4 }\end{array}$ & $\begin{array}{l}\text { Realize the importance of heritage } \\
\text { preservation for the community }\end{array}$ & 1.96 & 0.871 & CULT.B4 & $\begin{array}{l}\text { Share information about Qaitbay } \\
\text { Castle with visitors and tourists }\end{array}$ & 1.95 & 0.966 \\
\hline $\begin{array}{l}\text { CULT. } \\
\text { K5 }\end{array}$ & $\begin{array}{l}\text { Know the rules that must be } \\
\text { followed when visiting the Castle }\end{array}$ & 1.96 & 1.081 & CULT.B5 & $\begin{array}{l}\text { Follow the good hospitality } \\
\text { behaviors towards tourists }\end{array}$ & 2.01 & 1.024 \\
\hline $\begin{array}{l}\text { CULT. } \\
\text { K6 }\end{array}$ & $\begin{array}{l}\text { Know that Qaitbay Castle is an } \\
\text { important tourist attraction in Alex. }\end{array}$ & 3.38 & 1.669 & CULT.B6 & $\begin{array}{l}\text { Qaitbay Castle is one of the most } \\
\text { important places to spend holiday }\end{array}$ & 3.59 & 1.247 \\
\hline \multicolumn{4}{|c|}{ Gains from Tourism Advantages (GTA) } & \multicolumn{4}{|c|}{ Local Residents' Participation (LRP) } \\
\hline GTA.1 & $\begin{array}{l}\text { Tourism enhances people } \\
\text { understanding of cultural heritage }\end{array}$ & 1.73 & .771 & LRP1 & $\begin{array}{c}\text { I participated in activities related } \\
\text { to institutions that work in } \\
\text { heritage }\end{array}$ & 1.56 & 0.852 \\
\hline GTA.2 & $\begin{array}{l}\text { Tourism contributes to the } \\
\text { preservation of Qaitbay Castle }\end{array}$ & 1.79 & .952 & LRP2 & $\begin{array}{l}\text { I participated in heritage } \\
\text { conservation programs. }\end{array}$ & 1.57 & 0.716 \\
\hline GTA.3 & $\begin{array}{l}\text { Tourism leads to the development } \\
\text { of infrastructure and other public } \\
\text { services in the region }\end{array}$ & 1.95 & .972 & LRP3 & $\begin{array}{l}\text { I cooperated with local authorities } \\
\text { to develop the tourism activity in } \\
\text { the region. }\end{array}$ & 1.61 & 0.873 \\
\hline GTA.4 & $\begin{array}{l}\text { Tourism provides many job } \\
\text { opportunities }\end{array}$ & 2.00 & .933 & LRP4 & $\begin{array}{l}\text { I participated in courses or } \\
\text { workshops related to the cultural } \\
\text { heritage. }\end{array}$ & 1.65 & 0.889 \\
\hline GTA.5 & $\begin{array}{l}\text { Tourism can increase income and } \\
\text { improve standard of living }\end{array}$ & 2.025 & 1.047 & & & & \\
\hline GTA.6 & $\begin{array}{l}\text { Tourism provides the opportunity } \\
\text { for local products and handicrafts }\end{array}$ & 2.233 & 1.070 & & & & \\
\hline \multicolumn{2}{|r|}{ Overall M \& SD for GTA } & 1.955 & 0.432 & & Dverall M\&SD for LRP & 1.601 & 0.469 \\
\hline
\end{tabular}

Firstly, it was shown from Table 3 that all the statements of CULT.K variable were noted to be low (Over all M 2.14, SD 0.516), except the $6^{\text {th }}$ statement. Results explained that residents agreed on "Knowing that Qaitbay Castle is an important tourist attraction in Alex" ( $M$ 3.38), which had the greatest mean value. However, they didn't know the historical features of Qaitbay Castle ( $M$ 1.875).This indicated that their knowledge about Qaitbay Castle is only limited to that it is a popular tourist attraction in Alex, but they have no historical background about its great historical value. Secondly, regarding $C U L T . B$ 
statements, data in Table 3 showed that the least mean value is for the $1^{\text {st }}$ statement $\left(\begin{array}{ll}M & 1.60\end{array}\right)$. This is not surprising, as the decline of the mean scores of residents' knowledge towards their own culture and heritage will certainly affect their ability in dealing with tourists from different cultures. This result is supported by Idilfitri et al., in which they noted that people can't recognize other cultures while they have not enough knowledge about their own culture and heritage. ${ }^{44}$ In addition, this may be attributable that the study has been conducted in a popular area; most of its residents weren't able to deal and interact with different types of tourists. Moreover, residents didn't score a high mean value regarding the $3^{\text {rd }}$ statement $(M \quad 1.91)$. In this context, when asking residents about the existence of brochures, guidebooks or signs explaining the details of the place and directing them how to behave inside the Castle, most residents $(87.1 \%)$ confirmed that there are no means showing them the restrictions and regulations that must be followed inside the Castle.

Conversely, among CULT.B statements, the $6^{\text {th }}$ statement scored the greatest mean value $\left(\begin{array}{lll}M & 3.59\end{array}\right)$, than other items. It is worth mentioning that, when asking residents about the reasons for visiting Qaitbay Castle; five reasons were as follows respectively: the entry rates are inexpensive $(92.6 \%)$; an appropriate place for children and families $(91.5 \%)$; enjoying the sea view (87.4\%); accessibility to the Castle (79.6\%); and finally, visiting the Castle as a historical area was the last ranking (48\%). It can be concluded that the majority of residents visit Qaitbay Castle in holidays as a suitable place for low-income families. At the same time, they can enjoy beautiful sea and sunset view. So, Qaitbay Castle is one of the most important choices for local residents to spend holiday. This might be owing to the low standard of living in Qaitbay Castle area, as discussed previously. Also, the mean score of the $2^{\text {nd }}$ statement of CULT.B's proves this, indicating that visiting heritage sites is not considered in the top priorities of interest for residents. Consequently, the overall mean value of $C U L T . B$ is reported to be very limited (M 2.131, SD 0.505). This result might be due to the lack of residents' knowledge about the historical significance of heritage sites. Kisusi emphasized that, fostering residents' knowledge regarding cultural heritage helps in modifying and promoting their positive attitudes in heritage sites. ${ }^{45}$

Based on the above, the lower mean scores of CULT.K and CULT.B statements resulted in a lower level of CULT.AW among residents ( $M$ 2.135, SD 0.4182 ). These findings are consistent with what was said by most of interviewees regarding the lack of cultural awareness campaigns targeting Qaitbay Castle area in particular. As a result, local residents aren't aware of the cultural value of their region, which reflects the current situation in Qaitbay Castle area. It has become very crowded with many souvenir and street vendors who spread out on the Castle walkway in an uncivilized scene that disturbs citizens and Castle visitors. Moreover, letters of love on the walls of the Castle have destroyed its archeological structure. These unfavorable attitudes have caused many problems threatening the Castle, which necessitates intensifying awareness campaigns in this region as a fundamental footstep to preserve it. Afterwards, in order to know whether CULT.AW level varied among residents from one group to another according to their demographic characteristic, especially age and educational level, additional analysis based on an analysis of variance has been conducted as shown in Table 4

Table (4) One Way-ANOVA Test ( Age and Educational Variables)

\begin{tabular}{|c|l|c|c|c|c|c|}
\hline \multirow{2}{*}{} & & SSR & Df & Mean Square & F & Sig. \\
\hline \multirow{4}{*}{ Age } & $\begin{array}{l}\text { Between } \\
\text { Groups }\end{array}$ & 1.114 & 3 & .371 & 2.138 & .095 \\
\cline { 2 - 7 } & Within Groups & 82.867 & 477 & .174 & - & - \\
\cline { 2 - 7 } & Total & 83.982 & 480 & - & - & - \\
\hline \multirow{2}{*}{$\begin{array}{l}\text { Lducational } \\
\text { Level }\end{array}$} & $\begin{array}{l}\text { Between } \\
\text { Groups }\end{array}$ & 2.750 & 4 & .682 & 4.028 & $.003^{*}$ \\
\cline { 2 - 7 } & Within Groups & 81.232 & 476 & .171 & - & - \\
\cline { 2 - 7 } & \multicolumn{7}{|c|}{83.982} & 480 & - & - & \\
\hline
\end{tabular}

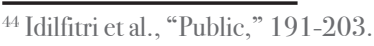

${ }^{45}$ Rahel Lucas Kisusi, "Promoting Public Awareness on the Existing Cultural Heritage Tourism Sites: A Case of Dar es Salaam City" (Masters thesis., The Open University of Tanzania, 2014), 1-142.
} 
Findings of ANOVA analysis showed that the level of residents' cultural awareness was unaffected by the age (Fratio 2.138 , $P$ value .095). Whereas, for the educational level; there was a statistically significant difference between groups according to their educational level. (F ratio 4.028, P value .003). Additionally, by analyzing data using Post-Hoc comparisons; it was shown that there was a significantly higher level of cultural awareness for those who held a bachelor degree $(M \quad 2.226, S D$ .4126) than other groups.

As for perceptions held by residents concerning their gains from tourism advantages $(G T A)$; the majority of residents are not supportive to the socio-cultural and environmental impacts as shown in Table 3 . On the other hand, the economic impacts had a moderate mean score regarding the $6^{\text {th }}$ statement, which represents the highest mean value among GTA statements (M 2.233). In this regard, several studies confirming that maximizing residents' gains from the tourism activity in the heritage site contributes in increasing their loyalty and belonging towards the targeted regions and motivating them to participate in preserving their cultural heritage. Hence, residents will realize that preserving heritage site is important for their source of livelihood. In other words, this induces them to protect their source of income. ${ }^{46}$

Eventually, regarding local residents' participation(LRP)in heritage site preservation (Qaitbay Castle), it was eliminated from Table 3 that there is a decline in their level of participation (Overall M $\quad 1.601, S D \quad 0.469)$. This might be owing to the lack of residents' cultural awareness; as well as, the minor benefit they get from tourism activity. Therefore, they aren't motivated to participate in protecting or developing the region. All in all, more cooperative efforts and programs are required from the official Parties in Alexandria to enhance locals' awareness regarding heritage and tourism and engage them in the conservation process. They must feel that heritage preservation is required for achieving sustainable tourism development in their area which brings positive impacts for them. ${ }^{47}$

As for the educational role played by schools ' $(S R)$ concerning raising students' cultural awareness, students’ feedback revealed the weakness of this role. All of $S R$ statements seem to be very limited as shown in Table (5):

Table (5) Mean and Standard Deviation Analysis of SR. Variables

\begin{tabular}{|c|c|c|c|c|}
\hline \multicolumn{2}{|r|}{ Statement } & $\mathrm{N}$ & M & SD \\
\hline SR.1 & curricula discuss the importance of heritage and tourism & 142 & 1.809 & .9297 \\
\hline SR.2 & School organizes trips to historical attractions (Qaitbay Castle). & 142 & 1.852 & .8908 \\
\hline SR.3 & School promotes positive behaviors towards environment and heritage. & 142 & 1.943 & .7511 \\
\hline SR.4 & Schools spreads knowledge about heritage and tourism & 142 & 2.063 & .8440 \\
\hline \multicolumn{3}{|c|}{ Overall M \& SD for SR. } & 1.917 & .6962 \\
\hline
\end{tabular}

Table (5) indicated that the overall Mean for the 4-statement school index was 1.917 with SD $\quad 0.696$. This indicated that there is a lack of the educational role played by schools in enhancing students' awareness regarding heritage and tourism, which need much improvement .Several studies emphasized that schools should educate students about their nation's heritage and teach them the positive behaviors towards heritage sites. ${ }^{48} \mathrm{As}$ it was mentioned in the theoretical part; there are various ways recently used to induce students to learn information in simplified and interesting ways to develop their sense of heritage. ${ }^{49} \mathrm{According}$ to Ahmed, an accumulative evaluation for students must be conducted through different methods; such as quizzes, reports, written material and competitions, to ensure better understanding of cultural heritage ${ }^{50}$ Eventually, the standard deviation of all the study variables refers to the moderation of data distribution and the lack of dispersion of the data.

\footnotetext{
${ }^{46}$ Kathleen Andereck, Christine Vogt, "The Relationship between Residents' Attitudes toward Tourism and Tourism Development Options,” Journal of Travel Research 39 (2000): 27-36; John Ap, “Residents’ Perceptions of Tourism Impacts,” Annals of Tourism Research 19, no. 4 (1992): 665-690.

${ }^{47}$ Aleksandra Terzić, Ana Jovičić and Nataša Simeunović-Bajić, “Community Role in Heritage Management and Sustainable Tourism Development: Case Study of The Danube Region In Serbia," Transylvanian Review of Administrative Sciences (2014): 183-201; Harrill, R, "Residents' attitudes toward tourism development: A literature review with implications for tourism planning," Journal of Planning Literature 18, (2004): 251-266; Pandey, "Sustainable," 1:72. ${ }^{48}$ Cooper and Shepherd, «The Relationship,» 34-47.

${ }^{49}$ Feifei Xu, Dimitrios Buhalis and Jessika Weber, “Serious games and the Gamification of tourism,” Journal of Tourism Management 60 (June, 2017): $244-$ 256.

${ }^{50}$ Ahmed, "Assessment,"1-26.
} 


\subsubsection{Deductive analysis of research hypotheses}

In order to test the study hypotheses and examine the relationships between variables; Linear and Step-Wise regressions analysis were conducted to explore. Firstly, the association between the two dimensions of cultural awareness (knowledge and behavior) and whether residents' behavior in heritage sites is affected by their knowledge or not. Secondly, testing the individual impact of CULT.AW and GTA on LRP was performed. Thirdly, an evaluation of the collective effect of the two main variables $C U L T$. $A W \& G T A$ on $L R P$ as a whole was carried out to predict the level of $L R P$ according to residents' cultural awareness and their gains from tourism advantages, assuming the stability of all other variables. The results of the regression statistical analysis are summarized in Table 6 .

Table (6) Regression Analysis for Study Hypotheses

\begin{tabular}{|c|c|c|c|}
\hline Dependent Variable & Independent Variable & \multicolumn{2}{|c|}{$\begin{array}{c}\text { (Knowledge) } \\
\text { (K.CULT) }\end{array}$} \\
\hline \multirow{8}{*}{$\begin{array}{l}\text { Behavior } \\
\text { (B.CULT) }\end{array}$} & $\mathrm{R}$ & \multicolumn{2}{|c|}{$.315^{* *}$} \\
\hline & R square & \multicolumn{2}{|c|}{.099} \\
\hline & Adjusted R ${ }^{2}$ & \multicolumn{2}{|c|}{.097} \\
\hline & Sig. & \multicolumn{2}{|c|}{.000} \\
\hline & $\beta$ value & \multicolumn{2}{|c|}{.315} \\
\hline & Std. Error of the Estimate & \multicolumn{2}{|c|}{.49011} \\
\hline & T value & \multicolumn{2}{|c|}{7.252} \\
\hline & $\mathrm{F}$ & \multicolumn{2}{|c|}{52.597} \\
\hline \multicolumn{2}{|c|}{ Hypothesis Testing } & \multicolumn{2}{|c|}{ H1 Supported } \\
\hline & & CULT.AW & GTA \\
\hline \multirow{8}{*}{$\begin{array}{l}\text { Local Residents' } \\
\text { Participation } \\
\text { (LRP) }\end{array}$} & $\mathrm{R}$ & $.493^{* *}$ & $.510^{* *}$ \\
\hline & R square & .243 & .260 \\
\hline & Adjusted $\mathrm{R}^{2}$ & .242 & .259 \\
\hline & Sig. & .000 & .000 \\
\hline & $\beta$ value & .493 & .510 \\
\hline & Std. Error of the Estimate & .40800 & .40339 \\
\hline & T value & 12.410 & 12.983 \\
\hline & $\mathrm{F}$ & 154.003 & 168.563 \\
\hline \multicolumn{2}{|c|}{ Hypothesis Testing } & \multicolumn{2}{|c|}{ H 2, 3 Supported } \\
\hline
\end{tabular}

H1. Local residents' behavior towards heritage site is affected by their cultural knowledge.

According to the regression analysis of CULT.AW dimensions, it was shown from Table 6 that B.CULT is positively correlated with K.CULT (Adjusted R $\quad .097$, Sig. (2-tailed) .000, $\beta$ value .315). Although K.CULT has alimited effect on B.CULT, it was shown to be a significant effect. This indicated that the more in-depth knowledge people have about cultural heritage, the more positive their behavior is towards heritage sites. Similarly, Nyaupane and Timothy found that people need to understand the value of cultural heritage and the important role they play in preserving heritage sites; then, their behavior can change over time, which undoubtedly contributes to make tourism sustainable in heritage sites. ${ }^{51}$ So, H1 was supported by the results of regression analysis.

H2. Local residents' participation in heritage site preservation is affected by their level of cultural awareness.

Table (6) demonstrated that LRP is positively affected by CULT.AW (Adjusted $R^{2} \quad 0.242$, Sig. 2-tailed $\quad 000<0.01$, $\beta$ value 0.493 ), which indicated that the high level of cultural awareness, the high level of residents participation in heritage

${ }^{51}$ Nyaupane and Timothy, «Heritage,» 225-239. 
preservation could be achieved. This result is congruent with the study of Bakri et al, who stated that cultural awareness is a valuable requirement for community participation in heritage preservation ${ }^{52}$. Additionally, Terry and Honggen substantiated that, enhancing locals participation could be reached through several methods; the most important one is raising cultural awareness. ${ }^{53}$ So, the second hypothesis $\mathrm{H} 2$ was supported through the regression analysis.

\section{H3. Local residents' participation in heritage site preservation is affected by their gains from tourism advantages.}

Table (6) tells us that there is a statistically significant and positive correlation (Sig.000< 0.01, Adjusted R $\left.R^{2} .259, \beta .510\right)$ between residents' gains from tourism advantages and their participation in heritage site preservation. This indicates that when local residents are feeling that the tourism activity in heritage sites has a great positive impact on their lives at all levels; they will be willing to participate in preserving the heritage site. This is in line with the study of Idilfitri et al., in which they noted that community oriented approach contributes in preserving heritage sites and achieving sustainable development. ${ }^{54}$ Taking local needs of residents into consideration, achieving a better quality of life for them, as well as involving them when planning and developing the region and providing funds for them to establish small projects; would certainly drive them to preserve their cultural heritage. ${ }^{55}$ So, H3 was supported by the results of regression analysis.

Table (7) Step-Wise Regression Analysis of Predictive Contribution of CULT.AW \&GTA on LRP

\begin{tabular}{|c|c|c|c|c|c|c|c|}
\hline & \multicolumn{9}{|c|}{ Dependent Variable (LRP) } \\
\hline Independent Variables & $\mathrm{R}$ & $\mathrm{R}$ Square & $\begin{array}{c}\text { Adjusted R } \\
\text { Square }\end{array}$ & $\begin{array}{c}\text { Std. Error of the } \\
\text { Estimate }\end{array}$ & $\begin{array}{c}\text { R Square } \\
\text { Change }\end{array}$ & $\mathrm{F}$ p-value \\
\hline GTA & 0.510 & 0.260 & 0.259 & .40339 & 0.260 & 168.563 & .000 \\
\hline GTA,CULT.AW & 0.586 & 0.343 & 0.341 & .38049 & 0.083 & 124.923 & .000 \\
\hline \multicolumn{7}{|c|}{ Pvalue is significant< $<0.05}$. \\
\hline
\end{tabular}

Eventually, after discussing the individual impact of CULT.AW and GTA separately on LRP, the researcher preferred to determine the collective effect of the two main variables (CULT.AW\&GTA) on LRP. Therefore, Stepwise regression analysis was employed to compute the highest significant predictor for LRP. The results are summarized as shown in Table 7.

Table (7) indicated that there is a statistically significant correlation between (CULT.AW \&GTA) as a whole and the LRP $\left(\right.$ Sig. $000<0.01$, Adjusted $\left.R^{2} \quad .341\right)$, which means that they had a collective significant effect on LRP. Additionally, it was illustrated that GTA is the best predictor of LRP. According to $R$ Square Change, $(26 \%)$ of the LRP could be predicted by GTA, while the contribution ofCULT.AW in improving LRP represents only $(8.3 \%)$. Finally, it can be said that the level of LRP could be positively increasing according to residents' cultural awareness and their gains from tourism advantages.

\section{Conclusion and Recommendations}

Heritage sites are significant tourist attractions and an important generator for the national income for many destinations. They are source of pride for the nation and evidence of its originality. Cultural awareness is the way through which the heritage sites can be preserved and protected ${ }^{56}$ Residents in Qaitbay Castle area have been examined concerning their level of cultural awareness, gains from tourism advantages and their participation in heritage preservation. Moreover, the study aims to discover the educational roles played by the governmental schools in Qaitbay Castle area in this regard. Descriptively, it was obvious that all the study variables were reported to be low. This is owing to the absence of an awareness comprehensive program organized by the official authorities, who work in heritage and tourism, targeting different categories in the local community. Unfortunately, each authority works independently, not according to an integrated or announced plan. Moreover, no awareness campaigns have been done periodically in different regions, as well as, the lack of cooperation with other external institutions. The findings also illustrated that the issue of cultural awareness has not yet gotten consideration among schools in the region of

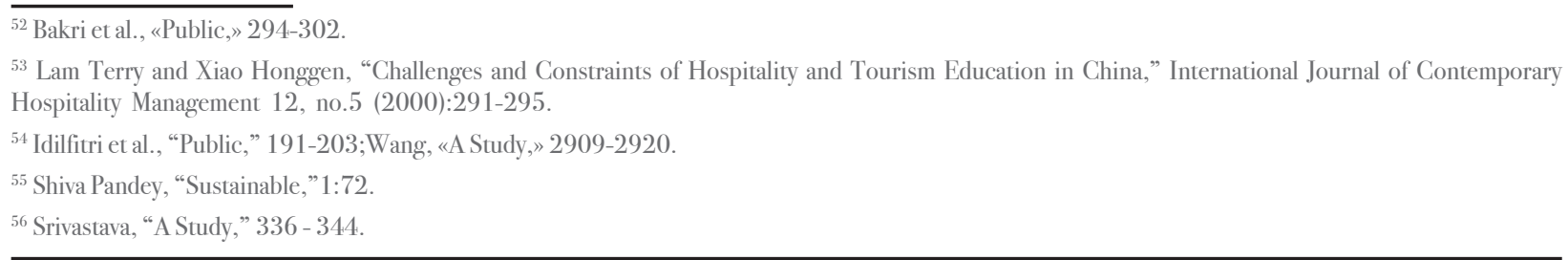


Qaitbay. Deductively, the results of regression analysis supported the hypothesis of the study. It was confirmed that there is a significant relationship between how much knowledge people have about the value of heritage sites and their positive behavior towards these sites. In addition, it was concluded that LRP is statistically correlated and affected by both CULT.AW and GTA. Furthermore, Step-Wise regression analysis proved that GTA is the best predictor for LRP, which suggests that local residents' participation in heritage preservation will increase if they actually get benefited from the tourism activity, realizing that the issue is related to their source of income, along with, planned awareness campaigns for raising their level of cultural awareness. Based on the above, the study presents some suggestions that should be considered: (1) Official entities, key actors, private sector and academic members should collaborate to draw an ambitious plan or develop a national project aiming at raising cultural awareness of the Alexandrian community and engaging people in taking responsibility of heritage preservation.

(2) Educational programs should be adopted in schools at all levels and implemented under the supervision of the Ministry of Tourism, Ministry of Antiquities and Ministry of Education in order to raise students' awareness. (3) Local administrations and councils need to pay more attention to what residents had to say concerning their thoughts about the region of Qaitbay Castle as they are considered the closest group to this cultural attraction and take into account the required procedures and policies that can improve residents' living standard. (4) Allocate specific places and establish small projects for those who are selling souvenirs and handicrafts away from the entrance of the Castle in the style of Khan El-Khalili Street in Cairo.

(5) Apply some tools to help achieve sustainability in Qaitbay Castle, such as: Environmental Impact Assessment (EIA), Carrying Capacity Calculation (CCC), Visitor Impact Management (VIM) and Land Use Plan (LUP).

(6) Supervision should be increased in Qaitbay Castle to control and minimize negative behaviors, along with providing brochures, electronic billboards and guidebooks that explain the rules and instructions which must be followed inside the Castle. (7) Relevant authorities should track the results of awareness campaigns that have been carried out in order to evaluate its effectiveness and determine points of strength and weakness. (8) Finally, the official bodies in the field of heritage and tourism should also activate festivals and special events that are appropriate to take place inside the Castle and in accordance with its value and nature, because this will stimulate tourism movement to the Castle on both the local and international level.

\section{Limitation and implications for further research}

This study can be used as a starting point for many ideas in this area of research in the future. The present research has been conducted in one region "Qaitbay Castle", other heritage sites in Alexandria with different samples should be examined to evaluate the level of community's awareness towards cultural heritage. A comparison between these regions should be conducted to determine the most priority regions for applying awareness campaigns in Alexandria. Also, the relation between the place of residence and the level of cultural awareness wasn't discussed in this study, so additional studies can focus on this point of research. The current study has drawn results from a random sample of residents including different segments of local community, more researches should be directed to investigate each segment of community separately to determine their level of awareness in the context of their characteristics, perceptions, problems and needs in order to draw a clear picture concerning the most suitable awareness program for each category.

Much research should investigate how to achieve integration between the official Parties in the field of tourism and heritage and other private institutions that are interested in heritage preservation. A comprehensive plan can be proposed by researchers for effective implementation of awareness campaigns in local communities. Further research is required to test more profile characteristics of residents and the relation to their degree of awareness. Furthermore, the current study focused on awareness regarding tangible heritage. Other researches should concentrate on intangible cultural heritage, such as traditions, rituals, local knowledge and artifacts, in order to ensure deeper understanding of cultural heritage. At the end, not much research has yet been done on different types of governmental and private schools in Alexandria, regarding their educational role in raising awareness which can be a further point of future research.

\section{Bibliography}

Abdelnaby, Heba. "Problems and Challenges of Cultural Heritage in Alexandria, Egypt." International Journal of Culture and History 3, no. 3 (September 2017): 174-178.

Ahmed, Tarek. "Assessment of Students' Awareness of the National Heritage, Case study: The Preparatory Year Students at the University of Hail, Saudi Arabia.” Cogent SocialSciences 3, no. 1 (2017): 1-26.

Aksu, Akin and Deniz Koksal. "Perceptions and Attitudes of Tourism Students in Turkey." International Journal of Contemporary Hospitality Management 17, no.5 (2005): 436-447.

Andereck, K.L. and G.P. Nyaupane. "Exploring the Nature of Tourism and Quality of Life Perceptions among Residents." Journal of Travel Research 50, no.3 (2011):248-260. 
Andereck, Kathleen, Christine Vogt. "The Relationship between Residents' Attitudes toward Tourism and Tourism Development Options," Journal of Travel Research 39 (2000): 27-36.

Antiquities Museum.Accessed December 10, 2017. http://Antiquities.Bibalex.Org/Home/Index.Aspx?Lang=Ar

Ap, John. “Residents' Perceptions of Tourism Impacts." Annals of Tourism Research 19, no. 4 (1992): 665-690.

Asta, Adukaite, Lorenzo Cantoni and Izak Zyl. "The role of digital technology in tourism education: a case study of South African secondary schools.” Journal of Hospitality, Leisure, Sport and Tourism Education 19 (2016): 54-65

Bakri, Fadzlin, Norhati Ibrahim, Sabarinah Ahmad and Qamaruz Zaman. "Public Perception on the Cultural Significance of Heritage Buildings in Kuala Lumpur.” Journal of Social and Behavioral Sciences 202 (2015): 294-302.

Buonincontri, Piera, Alessandra Marasco and Haywantee Ramkissoon. "Visitors' Experience, Place Attachment and Sustainable Behavior at Cultural Heritage Sites: A Conceptual Framework.”Journalof Sustainability 9, no.7 (2017): 1-19.

Cecil, Amanda, Yao-Yi Fu, Suosheng Wang and Sotiris Avgoustis. "Exploring Resident Awareness of Cultural Tourism and Its Impact on Quality of Life.” European Journal of Tourism Research 1, no.1 (2008):PP. 39-46.

Charlesworth, Zarina. "Educating International Hospitality Students And Managers: The Role Of Culture." International Journal of Contemporary Hospitality Management 19, no.2 (2007): PP.133-145.

Choi, Chris and ErcanSirakaya. "Measuring Residents' Attitude toward Sustainable Tourism: Development of Sustainable Tourism Attitude Scale.” Journal of Travel Research 43 (2005): 380-394.

Cooper, Chris and Rebecca Shepherd. "The Relationship between Tourism Education and the Tourism Industry: Implications for Tourism Education.” Tourism Recreation Research 22, no.1 (1997): 34-47.

Dallen Timothy and Boyd Stephen, Heritage Tourism (Harlow: Prentice Hall, 2003).

Dyer, P., D. Gursoy, B. Sharma and J. Carter. 'Structural Modeling of Resident Perceptions of Tourism and Associated Development on The Sunshine Coast, Australia." Tourism Management 28, no. 2 (2007): 409- 422.

Gould, Peter and Paul Burtenshaw," Heritage Sites: Economic Incentives, impacts, and Commercialization," In: Encyclopedia of Global Archaeology, edited by Claire Smith (Springer, London, UK,) 3326-3331

Gunlu, Ebru, Pirnar Ige, Kamil Yagci.” Preserving Cultural Heritage and Possible Impacts on Regional Development: Case of İzmir." International Journal of Emerging and Transition Economies 2, no.2 (2009): 213-229.

Harrill, R. "Residents' attitudes toward tourism development: A literature review with implications for tourism planning." Journal of Planning Literature 18, (2004): 251-266.

Http://www.dostor.org/2259969. Accessed February 19, 2018.

Huayhuaca, Ch'aska, Stuart Cottrell, Jana Raadik and Sabine Gradl. "Resident Perceptions of Sustainable Tourism Development: Frankenwald Nature Park.” International Journal of Tourism Policy 3, No. 2 (July, 2010): 126.

Idilfitri, Sabrina, Mohd Rodzi, Hanita Mohamad and Suria Sulaiman."Public Perception of the Cultural Perspective towards Sustainable Development." Social and Behavioral Sciences 168 (2015):191-203.

Kaae, B.C. "Tourism, Recreation and Sustainability." In: The perceptions of tourists and residents of sustainable tourism principles and environmental initiatives, edited by McCool, S.F. and Moisey, R.N, (Wallingford, 2000) 289-314.

Kathrin Machinek. "Qaitbay Fortress: Excavations and Study: A brief history," Accessed March 4, 2018, http://www.cealex. org/sitecealex/activites/terrestre/qaitbay/fort_qaitbay_intro_E.htm

Keitumetse, Osireditse."Heritage Enterprising: Cultural Heritage and Sustainable Tourism in Southern Africa." In: African Cultural Heritage Conservation and Management: Theory and Practice from Southern Africa, edited by Keitumetse, Osireditse, chap.7. 157-179, Switzerland: Springer, Cham, 2016.

Kisusi, Rahel Lucas. "Promoting Public Awareness on the Existing Cultural Heritage Tourism Sites: A Case of Dar Es Salaam City." (Master thesis., University of Tanzania, 2014) 1-142.

Mamhoori, A. "Sustainable Tourism Development: An Empirical Survey of Tour Operators In India.” Journal of Tourism and Hospitality 4, no.5 (2015): 1-6.

Mbaiwa, J.E. "The socio-economic and environmental impacts of tourism development on the Okavango Delta, North-Western Botswana." Journal of Arid Environments 54 (2003): 447-467.

Montoya, Castillo. "Preparing for Interview Research: The Interview Protocol Refinement Framework." The Qualitative Report 21, no.5 (2016): 811-831.

Mostafa Rasoolimanesh and Mastura Jaafar, "Community Participation toward Tourism Development and Conservation Program in Rural World Heritage Sites,” In: Tourism - From Empirical Research towards Practical Application, edited by: Leszek Butowski, (IntechOpen, 2016)1:14.

M. Saunders, P. Lewis and A. Thornhill, Research Methods for Business Students (London: Pearson Education, 2009) 176180.

Qaitbay, accessed December 22, 2017, http://www.egypt.travel/ar/attractions/qaitbay. 